\title{
THE SPECIFICITY OF RESERPINE IN THE TREATMENT OF SCHIZOPHRENIA IN IDENTICAL TWINS A CONTROLLED EXPERIMENT
}

\author{
BY \\ S. BENAIM \\ From The Bethlem Royal and Maudsley Hospitals, London
}

The occurrence of similar forms of psychiatric illness in identical twins was first reported by Galton (1883). More recent studies by Kallmann (1946) and Slater (1953) strongly indicate the importance of heredity in the aetiology of schizophrenia. The incidence of schizophrenia in one of a pair of uniovular twins when the other is affected by the disease has been stated by Slater and Kallmann to be $76 \%$ and $86 \%$ respectively. Because uniovular twins have an identical genetic constitution they provide scientific observers with an ideal opportunity for controlled investigations into the value of therapeutic measures. To the best of our knowledge, however, the present report is the first in the literature in which an investigation into the effects of various drugs has been carried out.

\section{Case History}

Eleanor and Audrey, 21-year-old twins, were admitted to the Bethlem Royal Hospital in January and May, 1956 , respectively, suffering from an acute schizophrenic illness.

They were the only children of healthy parents and there was no known family history of mental illness.

The patients were bottle fed for nine months and it was reported that neither girl walked till 20 months or talked till $3 \frac{1}{2}$ years old. Both had frequent temper tantrums, nightmares, and various fears; they were very jealous of each other and tended to be quarrelsome.

From the ages of 4 to 17 , the twins attended a number of schools, never distinguishing themselves and never forming stable relationships. There were frequent complaints by the school authorities to the effect that their lack of effort and mischievous behaviour set a bad example to the rest of the class. After eventually obtaining the General Certificate of Education they attended various secretarial and domestic science colleges, usually for short periods of time. Both had much difficulty in settling down to a job.

Menstruation began uneventfully at 12 and both girls suffered from premenstrual tension and irritability. At school, both had "crushes" for older girls: since leaving they had made only rare and superficial heterosexual contacts.
There was no history of previous physical illness other than the usual children's ailments.

The previous personalities are described as being very similar. Both were affectionate and attached to mother. They had many interests, mainly in ballet and music, but these were not sustained. They were keen on sporting activities, although not particularly proficient. With money they were extremely extravagant and generally irresponsible. The girls were very fond of each other although, when together, quarrelled frequently. Audrey was the dominant twin, preferred by their friends and acquaintances.

History of Illness.-The twins first fell ill in February, 1955 , within a few days of each other. The course of the illness will be described separately.

Eleanor was admitted to a hospital in the south of England on March 12, 1955 . On admission "she was very dissociated, and for long periods of the day seemed unable to maintain any contact with the real world. At such times she was agitated and half aware of her dissociation and unable to carry out any activity requiring attention or make more than passing contact with other people. She complained of a sense of unreality and if out on a walk would have no remembrance of the way home." It was considered that although "there was probably a schizophrenic overlay, her symptoms were mainly hysterical". She was treated with psychotherapy but made little progress during a stay of nine months. In January, 1956, she was transferred to the Bethlem Royal Hospital. She was found to be untidy, unkempt, hostile, uncooperative, inclined to scream suddenly and for no apparent reason, often becoming solitary and sullen. There was incongruity of affect and gross thought disorder typical of schizophrenia. She was treated with chlorpromazine, $100 \mathrm{mg}$. t.d.s., and reserpine, $2 \mathrm{mg}$. t.d.s., with some benefit: later, as she was improving, chlorpromazine was discontinued and reserpine gradually tailed off. By August, 1956, she was symptom free and was discharged home. She remained well for two months, although finding a secretarial course too exacting. In November, 1956, she developed paranoid delusions, became hallucinated and was readmitted to Bethlem Royal Hospital.

Audrey became ill a few days after her sister and showed similar symptoms. She was admitted to a 
TABLE I

COURSE OF ILLNESS

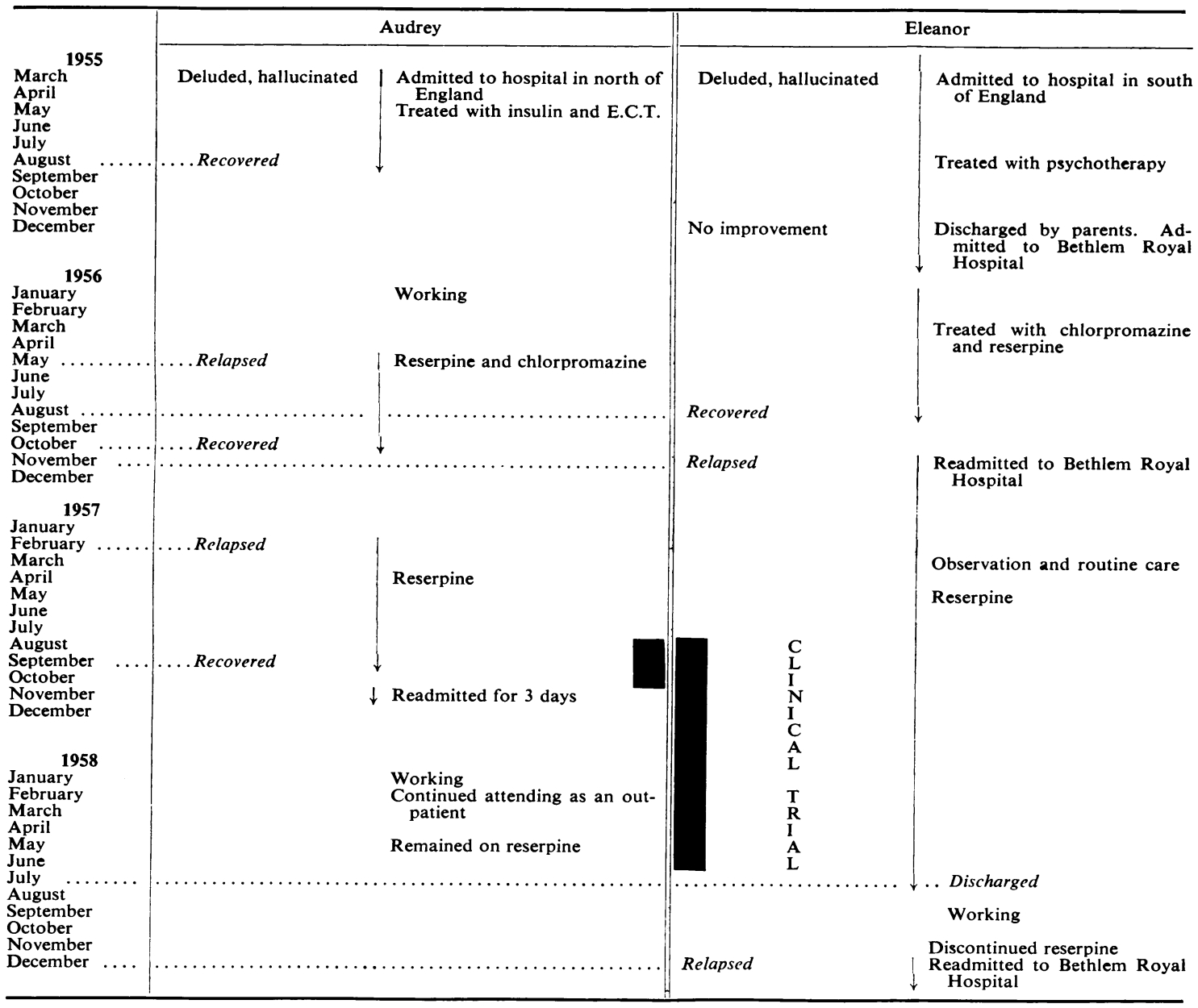

hospital in the north of England where a diagnosis of schizophrenia was made. She was subjected to a course of deep insulin comas and these were supplemented with a number of electroconvulsive treatments. Her recovery was rapid and she was discharged free of symptoms in August, 1955. After obtaining employment for a few months, she relapsed, was sacked on account of screaming attacks, developed paranoid delusions and hallucinations and was admitted to Bethlem Royal Hospital in May, 1956. She presented a picture of acute schizophrenia and was treated with reserpine in doses varying between 6 and $9 \mathrm{mg}$. daily. Once more she made a complete recovery and was discharged in October, 1956. Initially she settled well in a secretarial post but relapsed, and in February, 1957, she was readmitted.

During previous admissions both twins had responded to treatment with reserpine alone or in combination with chlorpromazine. To eliminate the possibility of improvement being due to a spontaneous remission, when Eleanor was admitted in November, 1956, it was decided that she should be observed and treated with routine medical and nursing care only. For 10 weeks such treatment produced no improvement and she remained deluded, hallucinated, showing affective incongruity and thought disorder. Rapid recovery followed the administration of reserpine and an equally rapid deterioration in the clinical condition occurred when a placebo was substituted. After reserpine was given again she improved once more.

When Audrey was admitted in February, 1957, she was treated with reserpine in the same dosage as her twin sister, i.e., $2 \mathrm{mg}$. t.d.s.: her response to this drug was equally dramatic as was also her relapse after the administration of a placebo.

From February, 1957, our patients were in hospital at 
the same time, under the care of the same doctor although in different wards. This separation was made necessary by the fact that during their illness the twins were particularly quarrelsome and intolerant of each other's behaviour. Moreover, after it was decided to carry out a controlled drug trial, it seemed vital to separate them in order to prevent one twin from affecting the clinical state of the other.

Investigations.-The following are the results of investigations:-

Height, Eleanor 67 in., Audrey 66 in.

Weight, Eleanor $146 \mathrm{lb}$., Audrey 144.5 lb.

Blood groups for both twins, $\mathrm{O}, \mathrm{MsNs}, \mathrm{P}+, \mathrm{R}_{\mathbf{1}} \mathrm{r}$, Lu $(\mathrm{a}-), \mathrm{K}-$, Le $(\mathrm{a}-\mathrm{b}+)$, Fy $(\mathrm{a}-)$

Wechsler intelligence quotient, full scale, Eleanor 95 and Audrey 94.

The Genetics Unit, Institute of Psychiatry (Mr. W. L. B. Nixon), reported as follows :

"Seen on March 26, 1957. Hair, eye colour, and single features indistinguishable. Phenylthiocarbamide test: both taste dilution 6 as 'bitter', can still taste dilution 9, not 13. Fingerprints: Total ridge counts-Eleanor 282, Audrey 294, Pattern type differences-2. Discriminant (Nixon, 1956) - L $=-3.082$, i.e., to the left even of the mean value for monozygotic twins. All above tests indicate that the twins are uniovular."

Experiment.-By the beginning of July, 1957, the twins had improved greatly and were receiving reserpine, $6 \mathrm{mg}$. daily. As from July 15, reserpine was gradually substituted by a placebo, in addition to which Audrey was given chlorpromazine in doses of $600 \mathrm{mg}$. daily and Eleanor meprobamate, $2,400 \mathrm{mg}$. daily: both were told that in addition to reserpine a second drug was being administered. From the onset of this trial the patients' mental state was assessed daily on a five-point scale as follows:-

0 - No abnormality of behaviour.

1 - Restlessness, irritability, untidy, and unkempt appearance.

2 - As above, plus ideas of reference.

3 - Deluded, hallucinated, autistic withdrawal.

4 - Gross psychotic behaviour necessitating transfer to a closed ward.

The mental state, the weekly weights, and the sequence of administration of the various drugs are shown in Fig. 1. Since each twin was used as her own control, their progress is best followed individually.

Audrey relapsed shortly after the substitution of reserpine by chlorpromazine, becoming deluded, hallucinated, and withdrawn. Although she began to show some improvement after chlorpromazine was substituted with a placebo, she did not regain her original state until reserpine therapy was begun again. Shortly after this she pressed to be discharged and was allowed to leave hospital on September 23, with the recommendation to continue taking $6 \mathrm{mg}$. reserpine daily. Her weight had increased by $16 \mathrm{lb}$. while receiving chlorpromazine but she had reverted to her original level soon after this drug was discontinued. With the exception of a three-day period when she was admitted to hospital after a quarrel with a landlady, Audrey has remained in the same secretarial post since her discharge. She has attended an out-patient clinic at regular intervals and her mental state has been assessed at each attendance. It was clear that each time she discontinued taking reserpine she became disturbed but in spite of repeated warnings she she would herself decide at times that the dose could be reduced or the drug discontinued altogether. As she was living in a room away from her family, there was no possibility of supervision. From April, 1958, until when last seen in January, 1959, she has maintained her improvement; her work is described as most satisfactory, she has made many social contacts and remains on reserpine, mg. 3 daily.

Eleanor also relapsed soon after the substitution of reserpine by a placebo. Since anxiety symptoms were prominent, it was decided to try the action of meprobamate, but her condition worsened and necessitated her transfer to a closed ward, chlorpromazine, $600 \mathrm{mg}$. daily, being administered as in the case of her twin sister. Since no improvement had resulted after a period of 12 weeks, reserpine therapy was begun again. with resulting improvement. When in January, 1958, the dose of this drug was reduced from 6 to $3 \mathrm{mg}$. daily, she became irritable, aggressive, and once more showed ideas of reference. These symptoms were relieved by reversion to the original dosage. When symptom free, it was decided to try once more the action of chlorpromazine on her illness. This decision was taken since, on the previous occasion, the introduction of a third drug, namely, meprobamate, could have confused the clinical picture. Once more, the substitution of reserpine with a placebo and the administration of chlorpromazine caused a re-exacerbation of symptoms which lasted till reserpine was again given. As in the case of her sister, she gained a considerable amount of weight while on chlorpromazine with a rapid loss when the drug was discontinued. She was discharged in July, 1958, obtained employment, and maintained her improvement while remaining on reserpine, $6 \mathrm{mg}$. daily. At the beginning of December, 1958, she stated that she had discontinued the drug, convinced that it was no longer helping her. She said that she was better without it than she had ever felt in her life. Her statements were confirmed by her mother and sister and it was decided to discontinue treatment. Later in the same month, however, she became difficult and unpredictable at work and was readmitted to Bethlem Royal Hospital, again showing incongruity of affect and schizophrenic thought disorder. Reserpine therapy was re-instituted and the patient is still in hospital at the present time.

\section{Discussion}

Psychotic illnesses in identical twins have been frequently recorded. Some studies have been descriptive, others, as those already mentioned, have stressed the importance of genetic factors and others still have been preoccupied with psychodynamic considerations (Benjamin, 1957). Case reports, such as that recorded by Kallmann (1938), describing the 

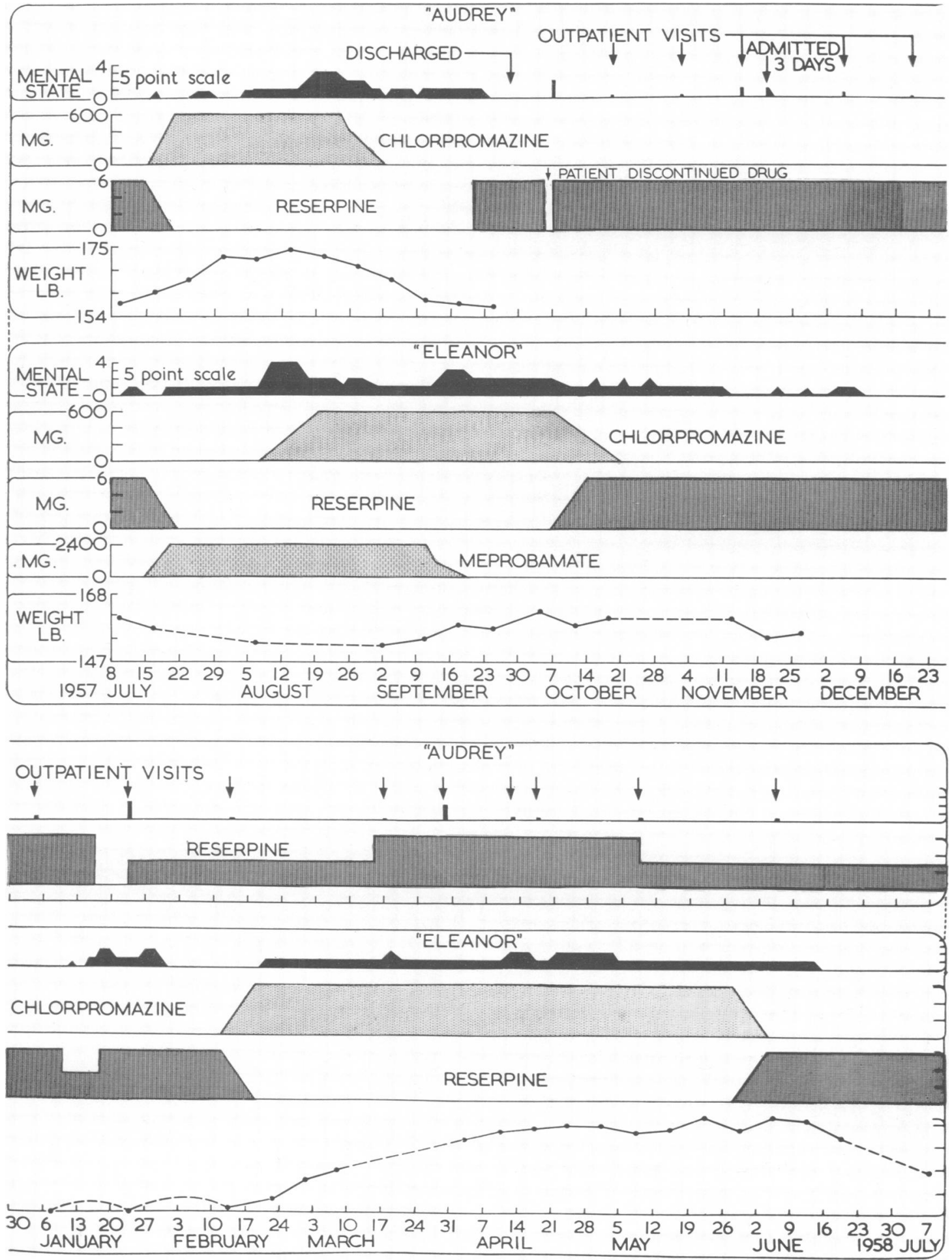
occurrence of schizophrenia within a few months of each other in twins that had been separated from birth, support strongly the case for a genetical inheritance of schizophrenia. While not denying the importance of psychodynamic considerations, the close relationship often found between identical twins and the fact that one often emerges as a dominant partner in the illness, we believe that the term "folie à deux" often used in the description of psychotic illnesses in twins, should be avoided, as it is only applicable to patients genetically unrelated.

One of the most interesting case reports in the literature is that of Weatherly and Deabler (1954). Identical twins, brought up together, developed schizophrenia within six months of each other while living apart. Ten years after the onset of their illness, the one who had responded only transiently to E.C.T. and insulin coma therapy was subjected to a leucotomy while the other, whose illness had been less severe and disabling, was not operated on. In a five-year follow-up, recently published (Weatherly and Deabler, 1958), it is reported that the operated twin had been working uninterruptedly since discharge "although at a modest level" and had made a satisfactory social adjustment even though at first he had seemed the worse prospect. The other twin had been in hospital on three occasions during the same five-year period. In this important study, one twin was used as a control for the other. The authors suggest the possibility that the second twin may be subjected to a similar operation in the future.

In the case reported here, the experiment was doubly controlled. In a first stage, one twin was treated with insulin and E.C.T., making a good but temporary recovery, whereas the other was treated with psychotherapy with no resulting improvement. It was interesting to note, moreover, that the latter twin was left with a more severely damaged personality and a liability to suffer more serious and prolonged relapses. In a second stage, both were treated with reserpine and chlorpromazine, each twin being used as her own control in a "blind" investigation. Not only did both respond to treatment with reserpine and relapsed when the drug was substituted with chlorpromazine, but they both required the same dose of the former drug. In addition their weight increased while on chlorpromazine and returned to its former level once this drug was discontinued and reserpine given again.

The comparison of the action of chlorpromazine and reserpine has been the subject of many investigations, in some of which controlled techniques have been employed. Lemere (1955) reports that in his opinion there is no advantage in using one rather than the other and that the same patient may not tolerate the one and yet respond to the other drug.
Rosner, Levine, Hess, and Kaye (1955) also found no significant differences in groups of patients treated with the two drugs. He noted, however, that the weight gain was greater with reserpine. Freeman, Arnold, and Cline (1956), in a double blind study, report that the two drugs had a similar effect on a group of chronic schizophrenic patients. The improvement noted was in the social adaptation of the patient rather than on the psychotic process itself. They comment on the fact that reserpine takes longer to act. A similar observation was made by Kovitz, Carter, and Addison (1955) who added that reserpine is of greater benefit where there is anxiety and hostility, while cases showing anxiety and tension are helped more by chlorpromazine. In a further controlled study, Shepherd and Watt (1956) found chlorpromazine much superior when given to a group of chronic schizophrenics and reserpine more likely to produce toxic and side effects. The dose of reserpine in this study (10$15 \mathrm{mg}$.) was, however, higher than that generally used.

It is clear from all this that the indications for the use of either drug are ill defined and the choice is a matter for individual preference. The specificity of reserpine in our case, however, seemed remarkable and cannot clearly be explained in our present state of knowledge.

The identical responses of the twins to the drugs $\stackrel{\mathbb{P}}{\mathrm{S}}$ used in this study can only be interpreted as further proof of their identical genetic constitution.

\section{Summary}

Identical twins developed a schizophrenic illness? within a few days of each other. One was treated with insulin coma therapy and E.C.T. and the other in a different hospital with psychotherapy with no resulting improvement.

When, in a later stage of their illness, both were admitted to the same hospital, a controlled drug trial was undertaken. Each twin responded to the same dosage of reserpine and relapsed when chlorpromazine was administered. There was a similar increase in weight while on the latter drug.

The similarity of their response is interpreted as further evidence of their identical genetic constitution.

Previous comparisons of the actions of chlorpromazine and reserpine are briefly discussed.

The patients were admitted under the care of Dr. W. Linford Rees and I wish to thank him for his help in planning this investigation and for permission to publish.

To Professor Sir Aubrey Lewis and Dr. Eliot Slater I am indebted for helpful advice and criticism. Finally, I am grateful to the Board of Governors of the Bethlem Royal and the Maudsley Hospitals for a grant from their research fund. 


\section{REFERENCES}

Benjamin, H. (1957). A.M.A. Arch. Neurol. Psychiat.. 78, 197. Freeman, H., Arnold, A. L., and Cline, H. S. (1956). Dis. nerv. Syst., 17, 213 .

Galton, F. (1883). Inquiries into Human Faculty and Its Development. Macmillan, London.

Kallmann, F. J. (1938). The Genetics of Schizophrenia. Augustin, New York.

- (1946). Amer. J. Psychiat. 103, 309.

Kovitz, B., Carter, J. T., and Addison, W. P. (1955). A.M.A. Arch Neurol. Psychiat., 74, 467.

Lemere, F. (1955). Ibid., 74, 1.
Nixon, W. L. B. (1956). “ On the Diagnosis of Twin-Pair Ovularity and the Use of Dermatoglyphic Data", Novant'anni delle Leggi Mendeliane, pp. 235-245, ed. L. Gedda. Instituto a Gregorio Mendel, Rome.

Rosner, H., Levine, S., Hess, H., and Kaye, H. (1955). J. nerv. ment. Dis., 122, 505.

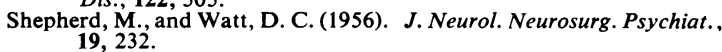

Slater, E. (1953). Spec. Rep. ser. Med. Res. Coun. (Lond.), No.

Weatherly, J., and Deabler, H. L. (1954). J. nerv. ment. Dis., $120,262$. 